\title{
The diagnostic role of microRNA-34a in breast cancer: a systematic review and meta-analysis
}

\author{
Saber Imani ${ }^{1,2}$, Xianqin Zhang ${ }^{1}$, Hossein Hosseinifard ${ }^{3}$, Shangyi Fu ${ }^{4}$, Junjiang Fu ${ }^{1}$ \\ ${ }^{1}$ Key Laboratory of Epigenetics and Oncology, The Research Center for Precision Medicine, Southwest Medical University, \\ Luzhou, Sichuan, PR China \\ ${ }^{2}$ Chemical Injuries Research Center, Baqiyatallah Medical Sciences University (BMSU), Tehran, Iran \\ ${ }^{3}$ Research Center for Evidence Based Medicine (RCEBM), Tabriz University of Medical Sciences, Tabriz, Iran \\ ${ }^{4}$ Honors College, University of Houston, Houston, TX, USA \\ Correspondence to: Junjiang Fu, email: fujunjiang@swmu.edu.cn, fujunjiang@hotmail.com
}

Keywords: breast cancer, microRNA-34a, biomarker, diagnostics, meta-analysis

Received: November 18, $2016 \quad$ Accepted: January 30, $2017 \quad$ Published: February 20, 2017

\section{ABSTRACT}

Background: MicroRNA-34a (miR-34a) is a master regulator of tumor suppression in breast cancer (BC). This systematic review aims to analyze the diagnostic accuracy of miR-34a in the detection of BC as a biomarker.

Results: A total of 1858 BC cases and 494 controls from thirteen eligible studies reported in 9 publications were included. The overall pooled sensitivity, specificity, negative likelihood ratio (NLR), positive likelihood ratio (PLR), and diagnostic odds ratio (DOR) were $85.50 \%$ (95\% CI: 83.80-87.00\%), 70.00\% (95\% CI: $65.80-74.10 \%$ ), 0.29 (95\% CI: 0.19-0.43), 2.58 (95\% CI: 1.91-3.43), and 9.39 (95\% CI: 5.47-16.12), respectively. Similarly, the overall area under the curve (AUC) of the summary receiver operating characteristic (SROC) was $\mathbf{0 . 8 0}$, indicating the high conservation of miR-34a as a biomarker. Furthermore, subgroup analysis suggested that the use of miR-34a as a biomarker is more accurate in tissue-based sample of invasive BC. We also indicated that miR-34a is a capable biomarker in diagnosing BC in people of Caucasian descent.

Materials and Methods: A systematic search was conducted for eligible publications that address miR-34a expression level in BC cases and noncancerous controls. Diagnostic capacity of miR-34a for BC was assessed using pooled sensitivity and specificity, DOR, and AUC of SROC. PLR and NLR were verified to estimate the miR-34a diagnostic accuracy in clinical level. The quality of the included studies was assessed by QUADAS-2.

Conclusions: These findings suggest miR-34a is a promising non-invasive biomarker in diagnosing BC. Well-designed cohort studies should be implemented to warrant the diagnostic value of miR-34a in clinical purposes.

\section{INTRODUCTION}

Breast cancer (BC) is the second leading cause of mortality in females worldwide and the most frequently diagnosed cancer in the USA, estimated $14.6 \%$ (1.68 million) of all new cancer cases and 40,290 of all cancer-related deaths in 2015 [1, 2]. Since the BC is a genetically heterogeneous disease, clinical and diagnostic outcomes are widely disparate and routine clinicpathological factors for diagnosis and/or prognosis of BC are potentially limited [3].
Certainly, early-stage detection and diagnosis of $\mathrm{BC}$ can reduce the mortality ratio, especially in some Asian-Pacific countries. Currently, mammogram screening for tissue- and serum-based tumor is the most effective screening tool for detecting the appearance or the recurrence of $\mathrm{BC}$ advancement [4, 5]. However, unavailability of hospital insurance, low sensitivity and specificity, high false positives, complexity, and high costs are main limitations of these diagnostic biomarkers to monitor disease progression or recurrence. For example, protein-based circulating tumor biomarkers, such as 
carbohydrate antigen 15-3 and tissue polypeptide specific antigen, are already applied in clinical diagnoses, but have low diagnostic sensitivity and specificity $[6,7]$. Therefore, novel noninvasive diagnostic biomarkers with high sensitivity and specificity for early-stage $\mathrm{BC}$ detection are in great need [8].

MicroRNA-34a (miR-34a) represents a novel class of tumor suppressor miRNA, which negatively represses the oncogene expression by binding to the $3^{\prime}$ UTR of target mRNAs [9]. MiR-34a can antagonize many different oncogenic processes; inhibit tumor cell differentiation, proliferation, migration and invasion; and increase apoptosis and cell arrest. As evidenced by current literatures, miR-34a is found to be the mediator of tumor suppression by transcriptional regulating p53, NOTCH, epithelial-mesenchymal transition (EMT), and TGF- $\beta$ signaling pathways [10-15]. Recent studies introduced miR-34a as a non-invasive urine-based biomarker for BC detection, with $61.0 \%$ sensitivity and $79.7 \%$ specificity [16-18]. Another study investigated the diagnostic accuracy of miR-34a by using fractionated radiation to create radiation-induced molecular targets [19]. A recently published study suggests that serum and plasma miR-34a levels were associated with the histologic grade of BC. However, there was no significant association between serum miR-34a expression and clinicopathologic features, such as hormone receptors and lymph node metastasis $[16,18]$. Therefore, we conducted a comprehensive, systematic review and meta-analysis based on eligible studies to solve inconsistent and ambiguous findings and confirm the diagnostic value of miR-34a in BC. Furthermore, we planned to document the evidence for the use of miR-34a as a diagnostic marker to predict other clinical pathological features and outcomes of BC.

\section{RESULTS}

\section{Literature search}

A detailed flowchart of the screening and selection process in systematic reviews and meta-analyses (PRISMA) is shown in Figure 1. In total, 651 potentially eligible studies were obtained according to the inclusion and exclusion criteria from database searching and 1 record by manual search. Afterwards, 278 papers potentially eligible for exclusions were confirmed with the initial search strategy mentioned. Of the 374 candidate studies, 216 studies were excluded due to unrelated titles or abstracts while 158 articles were left for abstract assessment. After carefully reviewing titles and abstracts, 124 studies were precluded for obvious irrelevance because of cell or animal studies data. Of the remaining 34 full-text candidate articles, 21 potential studies were excluded, due to insufficient data or data concerning either other cancers or other microRNAs studies. Finally, 9 articles were considered in this meta-analysis [16-18, 20-25].

\section{Main results and quality assessment}

The main clinical characteristics of the included studies were listed in Table 1 by order of quality assessment of diagnostic accuracy studies 2 (QUADAS-2) scores. Concerning the nine articles of interest, the first author, patient number, ethnicity, BC and sample type, characteristics of cases for each study as well as other necessary information were summarized. In total, 2352 subjects (1858 BC patients and 494 healthy controls) between 2010 and 2016 were included in our meta-analysis and histological classified into two types of BC $(n=13)$ : invasive breast cancer (IBC, $n=7$ ) and non-IBC (in situ) $(n=6)$. Of all the studies, 7 were focused on grade II/III BC (301 case) and 6 on grade I/II BC (1667 cases). MiR$34 \mathrm{a}$ expression levels were measured in formalin-fixed, paraffin-embedded tumor tissue $(n=5)$, serum $(n=3)$ and plasma $(n=1)$. While three studies used the in situ hybridization method, the quantitative real-time reverse transcription PCR (qRT-PCR) method was often used in the other studies to measure the expression of miR-34a by $2^{-\Delta \Delta C t}$ method with different reference controls $[17,24]$. Individually, the cut-off level of miR-34a appeared to be different (0.12-4.5) in different sample types. Notably, only two papers reported the sensitivity and specificity was directly extracted $[18,20]$. QUADAS-2 results showed that no significant bias was presented in current metaanalyses (Figure 2). Detailed information of QUADAS-2 assessment is represented in Supplementary Table 1.

\section{Quantitative synthesis}

The primary results of meta-analysis on the expression of miR-34a and BC risk are shown in Table 2. There were no significant associations between miR-34a levels and BC susceptibility for all genetic models. An overall analysis between miR-34a and odds ratios (ORs) was performed and results showed that all studies exhibit moderate heterogeneity $\left(\mathrm{I}^{2}=54.0 \%, P=0.048\right)$. Then, a random effects model was applied to calculate a pooled OR and 95\% confidence intervals (CIs), which were statistically significant in these cases (Table 2). Our results clearly showed heterogeneity of studies and analyses, so we then attempted to explain its sources from a randomized source of samples to calculate the accuracy of miR-34a. The threshold effect of spearman correlation coefficient is the main reason of heterogeneity in the test accuracy studies [26]. In this study, there was no heterogeneity from the threshold effect with the spearman correlation coefficient of sensitivity and 1 -specificity of $-0.415(P=0.158)$.

\section{Meta-analysis results}

\section{Diagnostic accuracy}

To assess the heterogeneity from threshold effect, we analyzed the diagnostic threshold with the spearman 
Table 1: Main characteristic of the included studies in this meta-analysis

\begin{tabular}{|c|c|c|c|c|c|c|c|c|c|c|c|c|c|c|c|c|c|c|}
\hline \multirow{2}{*}{$\begin{array}{l}\text { Author } \\
\text { (Ref.) }\end{array}$} & \multirow{2}{*}{ Year } & \multirow{2}{*}{ Country } & \multirow{2}{*}{ Ethnicity } & \multirow{2}{*}{ BC type } & \multirow{2}{*}{$\begin{array}{c}\text { Sample } \\
\text { type }\end{array}$} & \multicolumn{2}{|c|}{ Sample size } & \multicolumn{2}{|c|}{ Age } & \multicolumn{4}{|c|}{ Diagnostic power } & \multirow{2}{*}{$\begin{array}{l}\text { Cancer } \\
\text { grade }\end{array}$} & \multirow{2}{*}{$\begin{array}{l}\text { Cut-off } \\
\text { value }\end{array}$} & \multirow{2}{*}{$\begin{array}{l}\text { Genotyping } \\
\text { method }\end{array}$} & \multirow{2}{*}{$\begin{array}{l}\text { Meas. } \\
\text { type }\end{array}$} & \multirow{2}{*}{$\begin{array}{c}\text { Ref. } \\
\text { control }\end{array}$} \\
\hline & & & & & & Case & Cont. & $<\mathbf{5 0}$ & $>50$ & TP & FP & $\mathbf{F N}$ & TN & & & & & \\
\hline $\begin{array}{l}\text { Sanjay } \\
\text { Mishra } \\
{[18]}\end{array}$ & 2015 & India & Caucasian & Non-IBC & Plasma & 45 & 45 & NR & NR & NR & NR & NR & NR & II/III & 0.12 & qRT-PCR & TaqMan & U6 \\
\hline $\begin{array}{l}\text { Corinna } \\
\text { Eichelser } \\
{[20]}\end{array}$ & 2013 & Germany & Caucasian & $\begin{array}{c}\text { Non-IBC } \\
\text { IBC }\end{array}$ & Serum & $\begin{array}{l}120 \\
32\end{array}$ & $\begin{array}{l}40 \\
40\end{array}$ & $\begin{array}{l}0 \\
0\end{array}$ & $\begin{array}{l}120 \\
32\end{array}$ & $\begin{array}{l}\text { NR } \\
\text { NR }\end{array}$ & $\begin{array}{l}\text { NR } \\
\text { NR }\end{array}$ & $\begin{array}{l}\text { NR } \\
\text { NR }\end{array}$ & $\begin{array}{l}\text { NR } \\
\text { NR }\end{array}$ & $\begin{array}{l}\mathrm{I} / \mathrm{II} \\
\mathrm{II} / \mathrm{III}\end{array}$ & $\begin{array}{l}1.02 \\
4.5\end{array}$ & qRT-PCR & TaqMan & miR-16 \\
\hline Seema & & USA & & & & 407 & 54 & 127 & 334 & 354 & 15 & 53 & 39 & & & & & \\
\hline Agarwal & 2015 & USA & Caucasian & IBC & Tissue & 242 & 37 & 94 & 185 & 201 & 9 & 41 & 28 & $\mathrm{I} / \mathrm{II}$ & NR & In situ hyb. & NR & NR \\
\hline [17] & & Poland & & & & 705 & 90 & 270 & 525 & 672 & 26 & 33 & 64 & & & & & \\
\hline $\begin{array}{l}\text { Thalia } \\
\text { Erbes [16] }\end{array}$ & 2015 & Germany & Caucasian & Non-IBC & Serum & 24 & 24 & 24 & 24 & 19 & 6 & 5 & 18 & $\mathrm{I} / \mathrm{II}$ & 0.63 & qRT-PCR & TaqMan & miR-16 \\
\hline $\begin{array}{l}\text { Khan M.A. } \\
\text { [21] }\end{array}$ & 2016 & China & Asian & IBC & Tissue & 33 & 15 & 17 & 27 & 27 & 5 & 6 & 10 & II/III & 0.22 & qRT-PCR & TaqMan & U6 \\
\hline $\begin{array}{l}\text { Imen } \\
\text { Medimegh } \\
\text { [22] }\end{array}$ & 2014 & Tunis & Caucasian & Non-IBC & Tissue & 60 & 60 & 32 & 38 & 51 & 12 & 9 & 48 & II/III & 1.45 & qRT-PCR & SYBR & U6 \\
\hline $\begin{array}{l}\text { Mei YiWu } \\
\text { [23] }\end{array}$ & 2014 & China & Asian & Non-IBC & Tissue & 42 & 18 & NR & NR & 33 & 7 & 9 & 11 & II/III & 0.18 & qRT-PCR & TaqMan & U6 \\
\hline $\begin{array}{l}\text { Hanna } \\
\text { Peurala } \\
{[24]}\end{array}$ & 2011 & Finland & Caucasian & IBC & Tissue & 59 & 13 & 406 & 766 & 46 & 4 & 13 & 9 & II/III & 0.63 & In situ hyb. & NR & NR \\
\hline $\begin{array}{l}\text { Carina } \\
\text { Roth [25] }\end{array}$ & 2010 & Germany & Caucasian & $\begin{array}{c}\text { Non-IBC } \\
\text { IBC }\end{array}$ & Serum & $\begin{array}{l}59 \\
30\end{array}$ & 29 & NR & NR & 41 & 8 & 18 & 21 & $\begin{array}{c}\mathrm{I} / \mathrm{II} \\
\mathrm{II} / \mathrm{III}\end{array}$ & $\begin{array}{l}1.02 \\
4.5\end{array}$ & qRT-PCR & TaqMan & NR \\
\hline
\end{tabular}

Abbreviations: BC, breast cancer; IBC, invasive breast cancer; Non-IBC, non- invasive breast cancer; TP, true positive; FP, false positive; FN, false negative; TN, true negative; In situ hyb., in situ hybridization; qRT-PCR, quantitative real-time reverse transcription PCR; Meas., measurement; Ref, reference; U6, human U6 snRNA housekeeping small RNA controls; NR, not reported. All tissue samples are formalin-fixed, paraffin-embedded. "NR" parameters for the measurements type and reference control were considered as other categories. The fold changes in miR-34a expression were calculated using the $22^{-\Delta \Delta C \mathrm{C}}$ method. UD, unpublished data. Malignant tumors classified according the tumor-node-metastasis (TNM) stage.

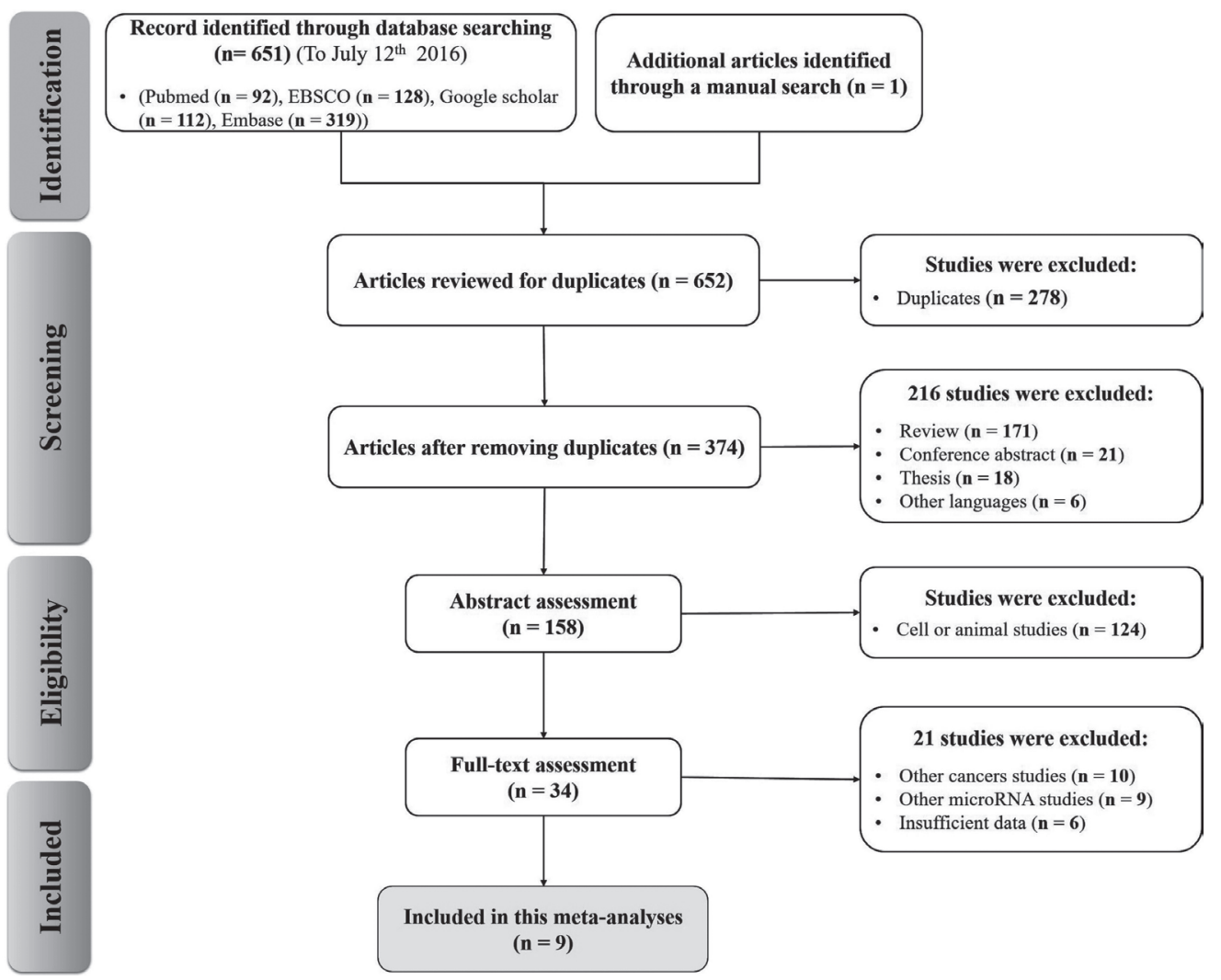

Figure 1: Flow chart of the study selection in the meta-analysis. 
Table 2: Meta-analysis results for the expression of miR-34a and breast cancer risk

\begin{tabular}{lcccccccc}
\hline & No. of studies & $\begin{array}{c}\text { Sample size (cases/ } \\
\text { controls) }\end{array}$ & $\mathbf{x 2}$ & I2 (\%) & $\begin{array}{c}\text { Pooling } \\
\text { Model }\end{array}$ & Pooled & OR (95\%CI) & $\boldsymbol{P}$-value \\
\hline Sensitivity & 13 & $1858 / 495$ & 166.79 & 92.80 & $\mathrm{R}$ & 85.5 & $83.80-87.00 \%$ \\
Specificity & 13 & $1858 / 495$ & 34.03 & 64.70 & $\mathrm{R}$ & 70.00 & $65.80-74.10 \%$ & 0.001 \\
PLR & 13 & $1858 / 495$ & 48.49 & 75.30 & $\mathrm{R}$ & 2.58 & $1.94-3.44$ & 0.007 \\
NLR & 13 & $1858 / 495$ & 118.81 & 89.91 & $\mathrm{R}$ & 0.29 & $0.19-0.43$ \\
DOR & 13 & $1858 / 495$ & 49.90 & 76.00 & $\mathrm{R}$ & 9.39 & $5.47-16.11$ & 0.001 \\
\hline
\end{tabular}

Abbreviations: OR, odds ratio; CI, confidence interval; PLR, positive likelihood ratio; NLR, negative likelihood ratio; DOR, diagnostic odds ratio; x2, chi-squared; R, randomize model.

correlation coefficient. The forest plots of pooled sensitivity, specificity, and diagnostic odds ratio (DOR) with their $95 \%$ CIs for individual studies are shown in the Figure 3. The overall pooled results for sensitivity, specificity, negative likelihood ratio (NLR), positive likelihood ratio (PLR), and DOR with their 95\% CIs were $85.50 \%$ (95\% CI: $83.80-87.00 \%$, Figure 3A), $70.00 \%$ (95\% CI: $65.80-74.10 \%$, Figure 3B), 0.29 (95\% CI: 0.19-0.43, Figure 3C), 2.58 (95\% CI: 1.94-3.44, Figure 3C), and 9.39 (95\% CI: 5.47-16.12, Figure 3E) respectively, which showed that there is no heterogeneity from the threshold effect of sensitivity and specificity $(P=0.158)$. The summary receiver operating characteristic (SROC) curve for the included studies was indicated in Figure $3 \mathrm{~F}$ with an overall area under the curve (AUC) of 0.8 and a partial AUC of 0.87 .

\section{Subgroup analyses}

Subgroup analysis was conducted based on ethnicity, cancer type, sample type, sample size $(\leq 100$ and $>100$ ), RNA measurement method, measurements type, reference control, and cancer grade. Table 3 reveals none of the above covariates contributed to the heterogeneity (all $P>0.05$ ). Therefore, on the basis of those covariates, the pooled sensitivity, specificity, AUC, and partial AUC for important sub-analysis parameters were measured. The subgroup analysis based on specimen types indicated that tissue has a relatively accurate diagnostic value in comparison to the serum, with a sensitivity of 0.897 versus 0.675 , specificity of 0.728 versus 0.630 , and AUC of 0.738 versus 0.737 (Figure 4A).

Furthermore, subgroup analysis of different BC types showed highter accuracy of miR-34a in detecting IBC samples (Figure 4B). As shown in Table 3 and Figure $4 \mathrm{C}$, the pooled sensitivity and specificity were higher in grade I/II of BC compared to grade II/III ( 0.873 versus $0.761,0.730$ versus 0.664 , respectively). Meanwhile, highest sensitivity, specificity, AUC, and partial AUC were shown in sample size more than 100, suggesting that miR-34a is more accurate in high sample size diagnosis (Figure 4D).

\section{Publication bias}

Funnel plots and Begg's test were used to estimate the publication bias, which was carried out repeatedly by precluding a single study at a time (Figure 5) [27]. The resulting shape of the funnel plot and Egger's test provided no statistical evidence for publication bias $(t=-2.90$, $P=0.148)$. Hence, there is no noticeable evidence for significant publication bias in our meta-analysis, which signifies our meta-analysis results were stable and credible.

\section{DISCUSSION}

It is well established that miRNAs have been considered as potential biomarkers in important

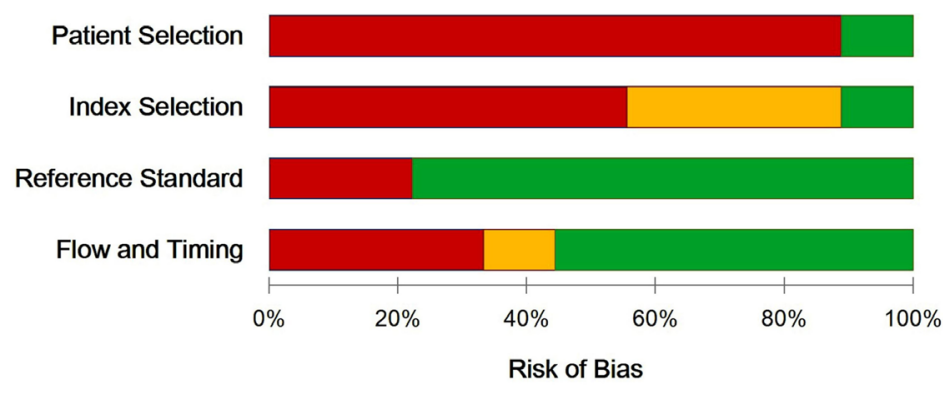

High

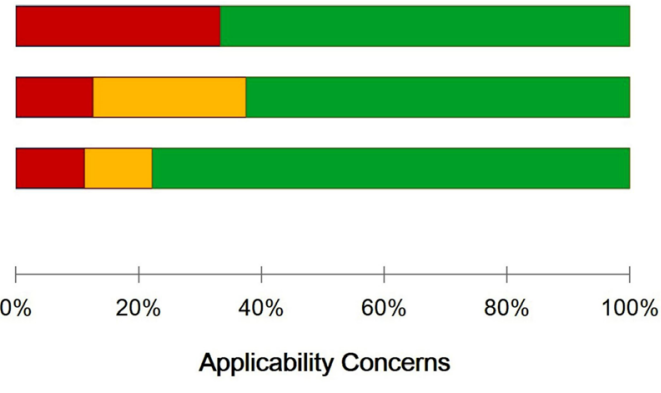

Unclear Low

Figure 2: The QUADAS score, risk of bias and applicability concerns graph for quality assessment. 
Table 3: Subgroup analyses of the included studies

\begin{tabular}{|c|c|c|c|c|c|c|c|c|c|}
\hline \multicolumn{2}{|c|}{ Subgroup analyses } & \multirow{2}{*}{$\begin{array}{c}\text { No. } \\
2(75)\end{array}$} & \multirow{2}{*}{$\begin{array}{c}\begin{array}{c}\text { Sensitivity } \\
\text { (95\% CI) }\end{array} \\
0.800 \\
(0.692-0.884)\end{array}$} & \multirow{2}{*}{$\begin{array}{c}\begin{array}{c}\text { Specificity } \\
\text { (95\% CI) }\end{array} \\
0.636 \\
(0.451-0.796)\end{array}$} & \multirow{2}{*}{$\begin{array}{c}\text { PLR } \\
\mathbf{( 9 5 \%} \mathbf{C I}) \\
2.184 \\
(1.373-3.476)\end{array}$} & \multirow{2}{*}{$\begin{array}{c}\text { NLR } \\
\mathbf{( 9 5 \%} \mathbf{C I}) \\
0.316 \\
(0.187-0.532)\end{array}$} & \multirow{2}{*}{$\begin{array}{c}\text { DOR } \\
\mathbf{( 9 5 \%} \mathbf{C I}) \\
6.970 \\
(2.809-17.296)\end{array}$} & \multirow{2}{*}{$\frac{\text { AUC }}{-}$} & \multirow{2}{*}{$\frac{\text { PAUC }}{-}$} \\
\hline D知 & Asian & & & & & & & & \\
\hline & Caucasian & $11(1783)$ & $\begin{array}{c}0.857 \\
(0.840-0.873)\end{array}$ & $\begin{array}{c}0.705 \\
(0.661-0.746)\end{array}$ & $\begin{array}{c}2.655 \\
(1.912-3.686)\end{array}$ & $\begin{array}{c}0.286 \\
(0.183-0.448)\end{array}$ & $\begin{array}{c}9.754 \\
(5.335-17.833)\end{array}$ & 0.804 & 0.879 \\
\hline \multirow{2}{*}{ Cancer type } & Non-IBC & $6(350)$ & $\begin{array}{c}0.689 \\
(0.637-0.737)\end{array}$ & $\begin{array}{c}0.755 \\
(0.692-0.810)\end{array}$ & $\begin{array}{c}2.768 \\
(2.172-3.325)\end{array}$ & $\begin{array}{c}0.394 \\
(0.282-0.553)\end{array}$ & $\begin{array}{c}7.227 \\
(4.194-12.455)\end{array}$ & 0.758 & 0.784 \\
\hline & IBC & $7(1508)$ & $\begin{array}{c}0.893 \\
(0.877-0.908)\end{array}$ & $\begin{array}{c}0.658 \\
(0.599-0.714)\end{array}$ & $\begin{array}{c}2.486 \\
(1.551-3.985)\end{array}$ & $\begin{array}{c}0.230 \\
(0.135-0.393)\end{array}$ & $\begin{array}{c}11.421 \\
(5.250-24.847)\end{array}$ & 0.808 & 0.886 \\
\hline \multirow{3}{*}{ Sample type } & Tissue & $7(1548)$ & $\begin{array}{c}0.894 \\
(0.878-0.909)\end{array}$ & $\begin{array}{c}0.728 \\
(0.673-0.779)\end{array}$ & $\begin{array}{c}3.123 \\
(2.583-3.776)\end{array}$ & $\begin{array}{c}0.197 \\
(0.125-0.310)\end{array}$ & $\begin{array}{c}16.304 \\
(8.988-29.572)\end{array}$ & 0.738 & 0.678 \\
\hline & Serum & $5(265)$ & $\begin{array}{c}0.675 \\
(0.615-0.731)\end{array}$ & $\begin{array}{c}0.630 \\
(0.550-0.704)\end{array}$ & $\begin{array}{c}2.135 \\
(1.304-3.396)\end{array}$ & $\begin{array}{c}0.478 \\
(0.389-0.587)\end{array}$ & $\begin{array}{c}5.070 \\
(3.180-8.084)\end{array}$ & 0.737 & 0.766 \\
\hline & Plasma & $1(45)$ & - & - & - & - & - & - & - \\
\hline \multirow{2}{*}{ Sample size } & $<=100$ & $9(384)$ & $\begin{array}{c}0.735 \\
(0.683-0.782)\end{array}$ & $\begin{array}{c}0.643 \\
(0.575-0.707)\end{array}$ & $\begin{array}{c}2.168 \\
(1.536-3.061)\end{array}$ & $\begin{array}{c}0.430 \\
(0.353-0.525)\end{array}$ & $\begin{array}{c}5.649 \\
(3.757-8.493)\end{array}$ & 0.759 & 0.787 \\
\hline & $>100$ & $4(1474)$ & $\begin{array}{c}0.880 \\
(0.863-0.896)\end{array}$ & $\begin{array}{c}0.744 \\
(0.689-0.794)\end{array}$ & $\begin{array}{c}3.266 \\
(2.672-3.990)\end{array}$ & $\begin{array}{c}0.194 \\
(0.094-0.398)\end{array}$ & $\begin{array}{c}17.149 \\
(7.536-39.024)\end{array}$ & 0.778 & 0.720 \\
\hline \multirow{2}{*}{$\begin{array}{l}\text { Genotyping } \\
\text { method }\end{array}$} & In situ hyb. & $4(1413)$ & $\begin{array}{c}0.901 \\
(0.884-0.916)\end{array}$ & $\begin{array}{c}0.722 \\
(0.653-0.783)\end{array}$ & $\begin{array}{c}3.205 \\
(2.554-4.022)\end{array}$ & $\begin{array}{c}0.167 \\
(0.089-0.314)\end{array}$ & $\begin{array}{c}20.141 \\
(9.407-43.125)\end{array}$ & 0.750 & 0.816 \\
\hline & qRT-PCR & $9(445)$ & $\begin{array}{c}0.708 \\
(0.663-0.750)\end{array}$ & $\begin{array}{c}0.687 \\
(0.631-0.739)\end{array}$ & $\begin{array}{c}2.370 \\
(1.649-3.407)\end{array}$ & $\begin{array}{c}0.404 \\
(0.313-0.522)\end{array}$ & $\begin{array}{c}6.429 \\
(4.234-9.763)\end{array}$ & 0.771 & 0.798 \\
\hline \multirow{3}{*}{ Ref. control } & miR-16 & $3(176)$ & $\begin{array}{c}0.676 \\
(0.602-0.745)\end{array}$ & $\begin{array}{c}0.577 \\
(0.476-0.673)\end{array}$ & $\begin{array}{c}2.025 \\
(0.965-4.250)\end{array}$ & $\begin{array}{c}0.455 \\
(0.305-0.678)\end{array}$ & $\begin{array}{c}4.953 \\
(2.630-9.326)\end{array}$ & 0.738 & 0.772 \\
\hline & U6 & $4(180)$ & $\begin{array}{c}0.756 \\
(0.686-0.819)\end{array}$ & $\begin{array}{c}0.754 \\
(0.673-0.823)\end{array}$ & $\begin{array}{c}2.789 \\
(1.973-3.944)\end{array}$ & $\begin{array}{c}0.330 \\
(0.183-0.595)\end{array}$ & $\begin{array}{c}8.555 \\
(3.823-19.141)\end{array}$ & 0.782 & 0.820 \\
\hline & other & $6(1502)$ & $\begin{array}{c}0.887 \\
(0.870-0.903)\end{array}$ & $\begin{array}{c}0.722 \\
(0.663-0.777)\end{array}$ & $\begin{array}{c}3.023 \\
(2.469-3.701)\end{array}$ & $\begin{array}{c}0.233 \\
(0.130-0.418)\end{array}$ & $\begin{array}{c}12.922 \\
(5.920-28.209)\end{array}$ & 0.733 & 0.656 \\
\hline \multirow{3}{*}{ Meas. type } & Taqman & $8(385)$ & $\begin{array}{c}0.686 \\
(0.637-0.732)\end{array}$ & $\begin{array}{c}0.658 \\
(0.595-0.718)\end{array}$ & $\begin{array}{c}2.162 \\
(1.550-3.015)\end{array}$ & $\begin{array}{c}0.476 \\
(0.402-0.564)\end{array}$ & $\begin{array}{c}5.224 \\
(3.580-7.625)\end{array}$ & 0.744 & 0.774 \\
\hline & SYBR & $1(60)$ & - & - & - & - & - & - & - \\
\hline & NR & $4(1413)$ & - & - & - & - & - & - & - \\
\hline \multirow{2}{*}{ Grade } & $\mathrm{I} / \mathrm{II}$ & $6(1557)$ & $\begin{array}{c}0.873 \\
(0.855-0.889)\end{array}$ & $\begin{array}{c}0.730 \\
(0.673-0.782)\end{array}$ & $\begin{array}{c}3.053 \\
(2.506-3.718)\end{array}$ & $\begin{array}{c}0.233 \\
(0.122-0.445)\end{array}$ & $\begin{array}{c}13.136 \\
(5.866-29.419)\end{array}$ & 0.752 & 0.778 \\
\hline & II/III & $7(301)$ & $\begin{array}{c}0.761 \\
(0.709-0.808)\end{array}$ & $\begin{array}{c}0.664 \\
(0.597-0.726)\end{array}$ & $\begin{array}{c}2.292 \\
(1.450-3.623)\end{array}$ & $\begin{array}{c}0.368 \\
(0.263-0.515)\end{array}$ & $\begin{array}{c}6.763 \\
(3.932-11.632)\end{array}$ & 0.782 & 0.804 \\
\hline
\end{tabular}

Abbreviations: IBC, invasive breast cancer; Non-IBC, non- invasive breast cancer; In situ hyb., in situ hybridization; qRT-PCR, quantitative real-time reverse transcription PCR; Meas., measurement; Ref., reference; U6, human U6 snRNA housekeeping small RNA controls; NR, not reported; AUC, area under the curve; PAUC, partial AUC; All study number reported as the number (case number); "NR" parameters for the measurements type and reference control were considered as other categories. The fold changes in miR-34a expression were calculated using the $2^{-\Delta \Delta C t}$ method. Malignant tumors classified according the tumor-node-metastasis (TNM) stage.

carcinogenesis processes related to angiogenesis, proliferation, differentiation, invasion, apoptosis, and metastasis. MiRNA's unique expression in cancerous tissue or serum, namely their stable up-regulation of oncogenic miRNAs or down-regulation of tumor suppressive miRNAs has deemed as potential biomarkers for diagnosis of various cancers. MiR-34a, as a potential tumor suppressive miRNA, was significantly down-regulated in variety of solid tumors. MiR-34a is involved in the invasion and migration process of $\mathrm{BC}$ by transcriptional regulating p53 network, indicating its potential role as a target for $\mathrm{BC}$ detection and therapy [15]. Significantly reduced circulating miR-34a levels in BC patients highlight the potential role of miR-34a as a novel non-invasive biomarker in BC [28]. Recently, Nugent et al. reported that miR-34a might be a potential biomarker for $\mathrm{BC}$ diagnosis because $\mathrm{BC}$ patients have higher serum miR-34a expression than healthy women, making this molecule a promising candidate as a biomarker to reflect various physiological and pathological states of $\mathrm{BC}$ $[25,26]$. These results suggest that biomarker can serve more use in the clinical settings if it is truly specific to a particular cancer type, which was partially demonstrated in the case of miR-34a.

With these assumptions and foregrounds, we collected all available studies and performed a metaanalysis to confirm the diagnostic value of miR-34a in the detection of $\mathrm{BC}$. We planned to understand the relationship of miR-34a as a diagnostic marker to predict other clinicpathological features and outcomes of BC, like cancer type, specimen type, cancer grade and sample size. To our best knowledge, no meta-analysis has investigated the association between BC and miR-34a expression by displaying consistent, statistically significant frequency in its expression level.

Conventional histological biomarkers for $\mathrm{BC}$ diagnosis, such as estrogen and progesterone receptors, and human epidermal growth factor receptor-2 
performances, fall short from perfect diagnostic methods, mainly due to their low diagnostic sensitivity and specificity, high cost and severe invasion [29, 30]. In addition, most computer-based diagnostic methods are rife complexity and instability. Meanwhile, the emergence of new molecular biomarkers, such as neuronspecific enolase [31], carcinoembryonic antigen [32], and cytokeratin-19 fragments [33], cannot be used in clinic settings due to low sensitivity and specificity [34]. Peurala et al. showed that low expression of miR-34a was found in about $32 \%$ of human breast carcinomas while high expression was in about $25 \%$, with the remaining tumors showing intermediate expression levels [24]. Our meta-analysis showed that vestibular schwannomas are

A

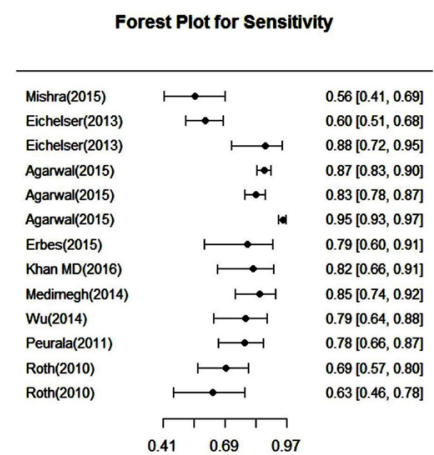

C

Forest Plot for Negative Likelihood Ratio

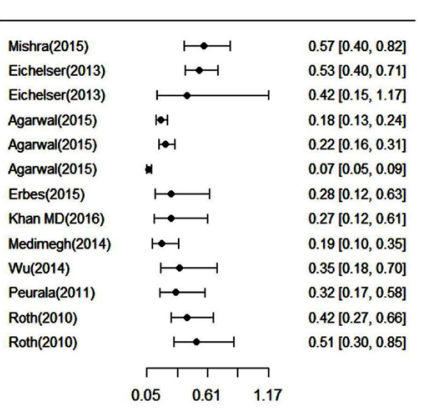

E

Forest plots of Diagnostic Odds Ratio (DOR)

\begin{tabular}{|c|c|c|}
\hline Mishra(2015) & 101 & $4.38[1.75,10.94]$ \\
\hline Eichelser(2013) & $10-1$ & $4.50[2.01,10.05]$ \\
\hline Eichelser(2013) & $n-1$ & $3.00[0.86,10.44]$ \\
\hline Agarwal(2015) & $10-1$ & $17.37[8.96,33.66]$ \\
\hline Agarwal(2015) & $1 \mapsto-1$ & $15.25[6.70,34.72]$ \\
\hline Agarwal(2015) & & $50.13[28.22,89.02]$ \\
\hline Erbes(2015) & $\stackrel{1}{\longrightarrow}$ & $11.40[2.95,44.00]$ \\
\hline Khan MD(2016) & $\stackrel{\longrightarrow}{\bullet-1}$ & $9.00[2.24,36.17]$ \\
\hline Medimegh(2014) & $\mapsto$ & $22.67[8.77,58.60]$ \\
\hline Wu(2014) & $10-1$ & $5.76[1.73,19.14]$ \\
\hline Peurala(2011) & . & $7.96[2.11,30.07]$ \\
\hline $\operatorname{Roth}(2010)$ & $\cdot-1$ & $5.98[2.23,16.01]$ \\
\hline Roth(2010) & $\theta-1$ & $4.53[1.51,13.65]$ \\
\hline
\end{tabular}

most highly ranked among consistently reported cancer types with down-regulated miR-34a (average FC: 1.43). It is unquestionable that down-regulation of miR-34a was significantly correlated with metastasis and an aggressive phenotype of BC $[15,35]$. Our findings also underlined an important association between miR-34a and BC risk (OR $=3.12,95 \%$ CI: $1.83-4.39, P<0.001)$. Subgroup analysis of cancer types showed significant association between the expression of miR-34a and increased relative risk of IBC $(\mathrm{OR}=0.90,95 \% \mathrm{CI}: 0.877-0.908, P=0.02)$, well as tissue-based samples (OR $=0.894,95 \%$ CI: 0.878-0.909, $P=0.001)$. Also, a significant diagnostic role of miR-34a was found in large sample sizes than size of less than 100 cases. Our results also suggested miR-34a had more

B

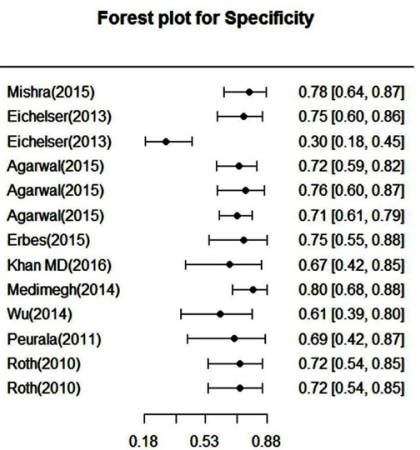

D

Forest Plot for Posetive Likelihood Ratio

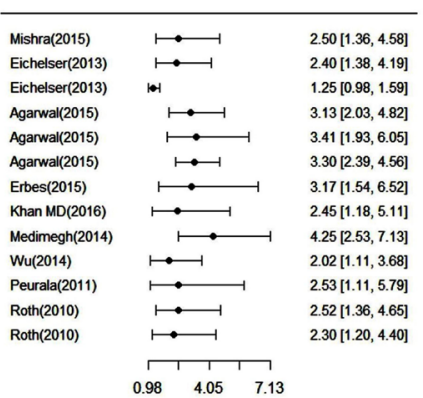

$\mathbf{F}$

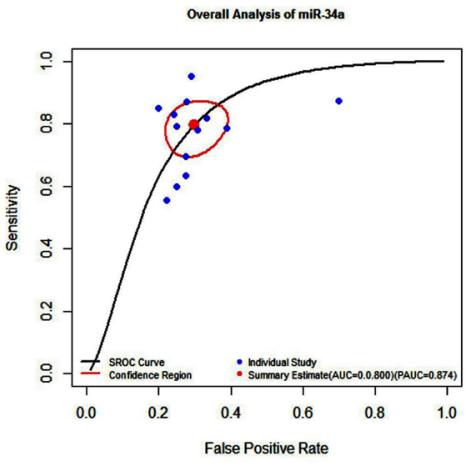

Figure 3: Forest plots of pooled sensitivity (A), specificity (B), negative likelihood ratio (C), positive likelihood ratio (D), diagnostic odds ratio $(\mathbf{E})$ and summary receiver operating characteristic (SROC) curve (F) for miR-34a in the diagnosis of breast cancer. 
promising accuracy for BC diagnosis in Caucasians than that in Asian patients. It is already well established that miRNA expression profiling might be more precise in the Caucasian population than the Asian population [36]. Considering the limitation of small sample size in the Asian group, further large-size studies among Asian BC population should be designed to provide a comprehensive outcome. Our systematic search clearly indicated that African-American populations, as well as Hispanics, were associated with a risk factor for developing particular forms of $\mathrm{BC}$. $\mathrm{ER}^{+} \mathrm{BC}$ tends to be associated with Caucasian women, and triple-negative breast cancer tends to be associated with ethnicity/race [37, 38]. MiR-34a is more accurate in a large cohort study of tissue-based IBC. Due to the relatively low overall accuracy based on pooled sensitivity and specificity, the diagnostic accuracy may not be as high as expected. Furthermore, we combined the pooled DOR and SPE data with sensitivity to assay the test accuracy. However, the higher value of DOR represents better test discernment [36].

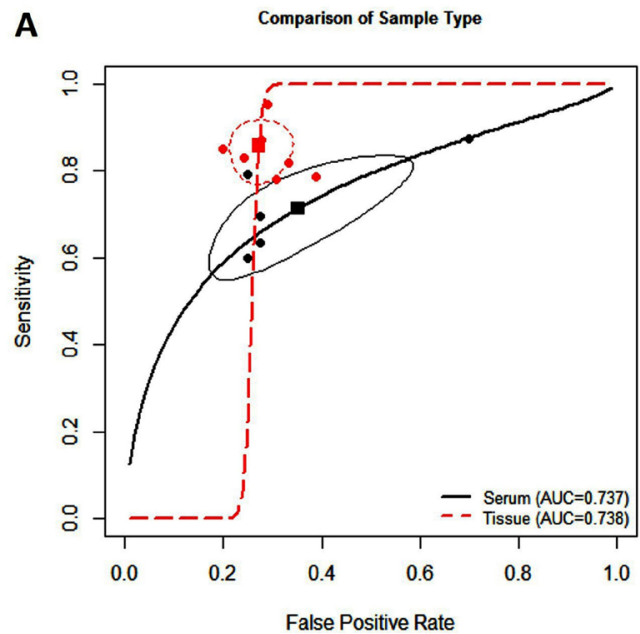

C

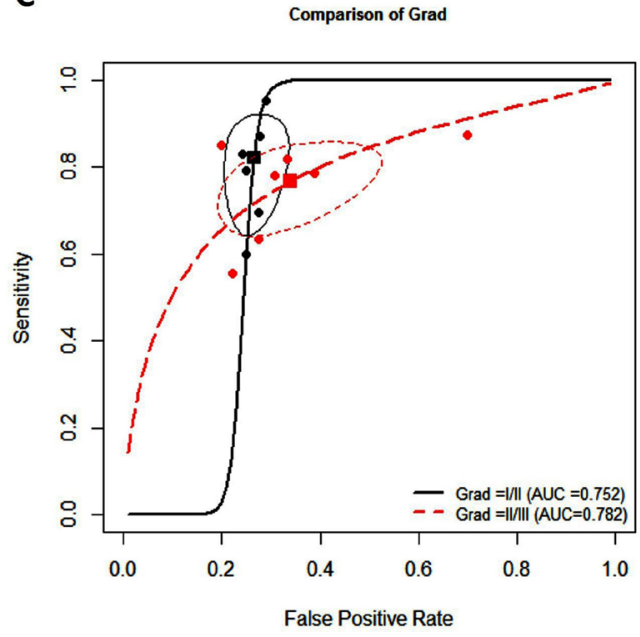

The assessment of diagnostic accuracy of miR-34a in clinical level was verified by PLR and NLR likelihood ratios test. NLR value of 0.289 (95\% CI: $0.19-0.43$ ) indicated that the possibility of the person having $\mathrm{BC}$ is around 3\% if miR-34a evaluations were negative, which is low enough to rule out cancer. Pooled PLR of 2.58 (95\% CI: 1.94-3.43) suggested that BC patients could have about 2.58-fold higher chance of being miR-34a positive compared to healthy control. Specifically, the upperleft corner SROC curve is the perfect test to evaluate diagnostic value [39]. Our overall AUC of SROC is 0.84, indicating miR-34a is highly accurate as a biomarker for BC. Statistically 0.80 AUC and 0.874 partial AUC are considered in good range of SROC (the good range of AUC: 0.75-0.92 [40]).

Sources of interpatient heterogeneity had a critical role in affecting the robustness of meta-analysis results, thus important for calculating the accuracy of miR-34a from randomized samples source. The threshold effect of spearman correlation coefficient is the main reason for

B Comparison of Cancer Type

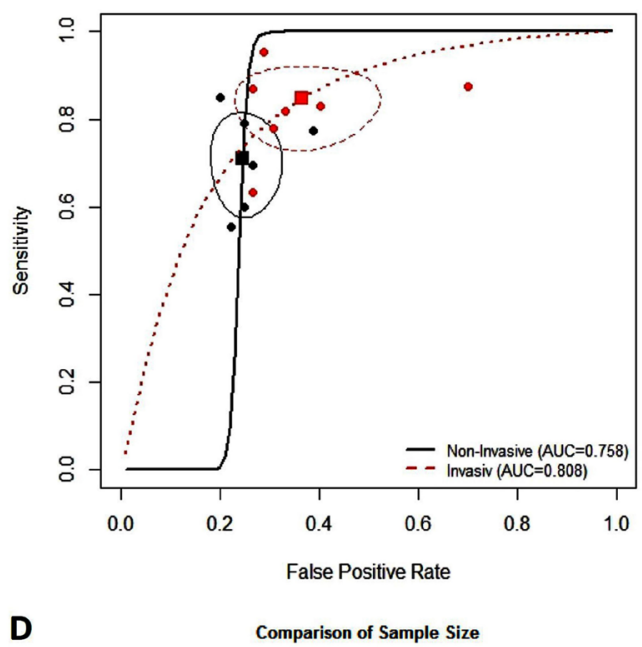

D

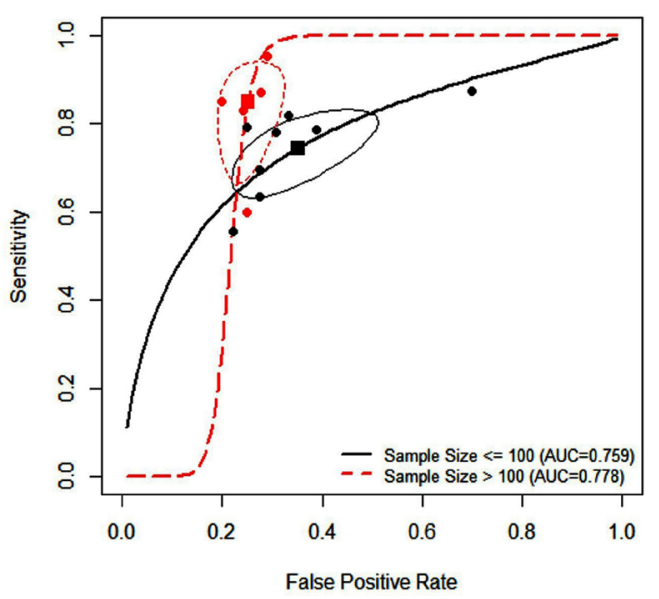

Figure 4: Summary receiver operating characteristic curve for miR-34a and subgroup analysis based on specimen types (A), breast cancer type (B), breast cancer grade $(\mathbf{C})$, and sample size $(\mathbf{D})$. 
heterogeneity in tested accuracy studies [26]. In this study, there was no heterogeneity from the threshold effect with the spearman correlation coefficient of sensitivity and 1 -specificity of $-0.415(P=0.148)$. Even so, we performed meta-regression and subgroup analysis to implement other related factors that affecting heterogeneity. For instance, qRT-PCR was extensively used to test miR-34a expression with the human U6 snRNA as control [41, 42]. Subgroup analysis showed that tissue-based miR-34a had higher accuracy for diagnosing $\mathrm{BC}[41,42]$. Other results of different subgroups were relatively consistent with the main results, which proposed that our findings are reliable.

We should point out that there are some limitations in this investigation. First, we only included the papers in English language, while published papers in other languages were ignored. Fundamentally, the meta-analysis results were based on unadjusted estimates, because some studies did not provide detailed information to calculate the adjusted estimates. Furthermore, many confounding factors were not controlled or reported in biased statistical results. For example, the unadjusted ORs, specific genetic factors (e.g. BRCA1/2 mutations), and many other clinical factors such as age might lead to bias. In addition, very few African populations (60 cases) were involved in our analysis [22], which may cause selection bias from population. Small sample size, quality of the original studies, and poor homogeneous distribution of the population based on subgroup parameters might be other limitations in our study as well. Well-designed studies in large-scale with matched case-controls and functional studies are of great value to warrant these findings.

\section{MATERIALS AND METHODS}

\section{Search strategy}

A comprehensive systematic search from the literatures published in English was carried out by querying the MEDLINE electronic database, including PubMed, ISI Web of Science, Google Scholar, vendor information pages database, and Embase, to identify all the relevant studies. Based on the research question, the following key words or main heading term were used: "microRNA-34a or micro RNA 34a or miRNA-34a or miR-34a", "breast or mammary", "cancer or neoplasm or carcinoma", and "tumor or tumour", Alternative spelling and synonyms were incorporated using Boolean "OR" and main terms were linked using Boolean "AND". All literatures assessed the diagnostic value of miR-34a in BC patients are prior to July 12, 2016, no lower date limit was used. References of articles were also checked for any relevant articles.

\section{Study inclusion/exclusion criteria}

Studies were considered eligible if they met the following criteria: (i) BC was confirmed by histopathological examination; (ii) the levels of miR$34 \mathrm{a}$ in tissue or plasma or serum were measured; (iii) the association between the expression level of miR-34a and survival outcomes, like sensitivity, specificity, and cutoff values can be found in each study or measured from the provided data. Exclusion criteria in this meta-analysis

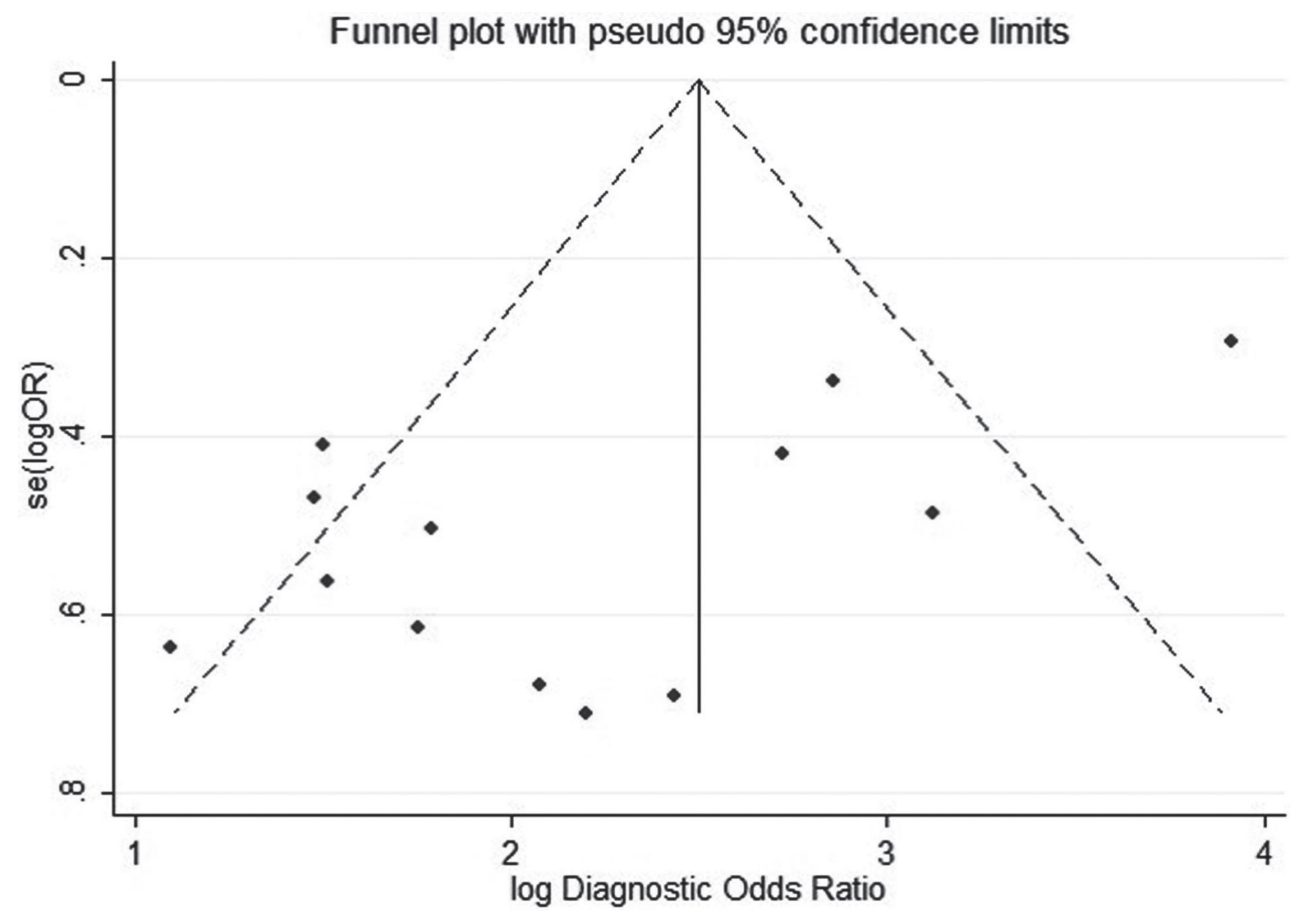

Figure 5: Publication bias by Funnel plot analysis. Each point represents a separate study for the indicated association, the vertical axes represent standard error of logarithmic hazard ratio (HR) and horizontal axes represent the HRs limits. 
were as follows: (i) a review, case-control, conference abstract, meeting, comments, letter or experiment on cell line and animal model; (ii) non English articles; (iii) duplicates or continued works of previous publications; (iv) unqualified key data such as ORs with their 95\% CIs, inadequate $P$-value, or useful data calculated by Tierney et al. [43], Williamson et al. [44], and Parmar et al. [45]; (v) articles from one author and the studies with repeated samples from the same patients when a study already included.

\section{Data extraction}

The following key components of all qualified studies were recorded independently by two investigators (XZ and SI): first author's name, publication year, country origin, $\mathrm{BC}$ type, characteristics of controls and matching criteria, study design, tumor-node-metastasis stage, tumor size, sampling site, ethnicity, genotyping methods, reference control, RNA extraction, measurement methods, total number of cases and controls, cut-off value, $P$-value for Hardy-Weinberg equilibrium (HWE) of controls, and true and false positives and negatives [43]. Any inconsistencies or disagreements in the research process were resolved through debate and consultations. If they could not reach a consensus, a third partner (JF) resolved these disagreements according to the original data. We also e-mailed the corresponding authors of the selected articles to obtain any missing or additional information and copies of the original data required for the meta-analysis.

\section{Quality assessment}

This present study was performed systematically in accordance with the guidelines of the preferred reporting items for PRISMA [46]. Diagnostic accuracy of studies was validated by QUADAS-2 tool in patient selection, index test, reference standard, and flow timing [47]. QUADAS-2 was assessed to determine the quality of all the studies by three authors (XZ, SI and $\mathrm{HH}$ ) and any disagreements were resolved through a discussion. Each of the assessment was subjected to seven questions with the answered with "yes", "no", or "unclear". The answer of "yes" means that a study's risk bias can be judged as low, while "no" and "unclear" mean that the risk of bias can be referred as high. The quality assessment table for each selected study is sorted in Supplementary Table 1.

\section{Statistical analysis}

Meta-analysis was performed using Manager Software version 5.2 (software update; The Nordic Cochrane Centre, Copenhagen, Denmark). Data was presented as mean \pm Std. deviation (SD) or median (range), including a description of qualitative variables such as number and percentage. Pooled sensitivity, pooled specificity, PLR, NLR, DOR, and corresponding 95\% CIs were calculated to evaluate the diagnostic value of miR$34 \mathrm{a}$. HWE was checked by $\chi^{2}$ test. The heterogeneity of the combined DOR was evaluated with Cochran's $Q$ test and the Higgins I-squared statistic from non-threshold effect. To identify cut-off threshold effects, spearman's rank correlation coefficient test was used to determine associations between two sensitivity and specificity [26]. They were considered statistically heterogeneous if they displayed $P<0.05$ and/or I2 $>50 \%$ [48]. Subgroup analysis was conducted to determine the source of existing heterogeneity. The diagnostic threshold effect was analyzed by the Spearman correlation coefficient test. Additionally, we examined the correlation between miR-34a expression and the clinicopathological variables in BC through OR [49]. Forest plot was used to estimate the diagnostic effects of miR-34a expression on $\mathrm{BC}$ diagnosis. Publication bias was evaluated by funnel plot and Egger's regression test [50]. The value less than 0.05 for " $\operatorname{Pr}>|z|$ " was considered as potential publication bias $[48,50]$. All reported $P$ values were two-sided and $P<0.05$ was considered statistically significant. All statistical analyses were carried out using MetaDiSc version 1.4 and $\mathrm{R}$ software (version 3.3.1) packages included "mada" (for sensitivity and specificity analysis).

\section{CONCLUSIONS}

Despite some limitations, the data of the present meta-analysis suggests that miR-34a displays excellent characteristics in $\mathrm{BC}$ detection as well as exhibits characteristics of a more accurate diagnostic biomarker in tissue samples of IBC patients. Furthermore, our metaanalysis indicates that miR-34a could be a promising and novel non-invasive biomarker in diagnosing BC.

\section{ACKNOWLEDGMENTS}

We gratefully acknowledge all authors for her/his ongoing collaborations with us in replaying and sharing their information. We also thank Professor X. Xiao from the Department of Pathology at the Affiliated Hospital of Southwest Medical University for pathologic counseling.

\section{CONFLICTS OF INTEREST}

The authors declare that there is no conflicts of interest that could be perceived as prejudicing the impartiality of the research reported.

\section{FUNDING}

This work was supported by the National Natural Science Foundation of China (81672887, 81172049), Science and Technology Innovation Team of Colleges 
and Universities of Sichuan Province (13TD0032), the Research Foundation of the Science and Technology Department of Sichuan Province (14JC0797, 2015JY0038) and Luzhou City Special Foundation.

\section{Authors' contributions}

S.I. and J.F. was in charge of idea and designed the study. X.Z. and S.I. searched and collected the data. H.H. performed data analyzing. S.I., S.F. and J.F. wrote the manuscript and were in charge of language revision. All authors reviewed and approved the manuscript.

\section{REFERENCES}

1. DeSantis CE, Fedewa SA, Goding Sauer A, Kramer JL, Smith RA, Jemal A. Breast cancer statistics, 2015: Convergence of incidence rates between black and white women. CA Cancer J Clin. 2016; 66:31-42.

2. Siegel RL, Miller KD, Jemal A. Cancer Statistics, 2017. CA Cancer J Clin. 2017; 67:7-30.

3. Cancer Genome Atlas N. Comprehensive molecular portraits of human breast tumours. Nature. 2012; 490:61-70.

4. Taplin S, Abraham L, Barlow WE, Fenton JJ, Berns EA, Carney PA, Cutter GR, Sickles EA, Carl D, Elmore JG. Mammography facility characteristics associated with interpretive accuracy of screening mammography. J Natl Cancer Inst. 2008; 100:876-887.

5. Sturgeon CM, Duffy MJ, Stenman UH, Lilja H, Brunner N, Chan DW, Babaian R, Bast RC Jr., Dowell B, Esteva FJ, Haglund C, Harbeck N, Hayes DF. National Academy of Clinical Biochemistry laboratory medicine practice guidelines for use of tumor markers in testicular, prostate, colorectal, breast, and ovarian cancers. Clin Chem. 2008; 54:11-79.

6. O'Hanlon DM, Kerin MJ, Kent P, Maher D, Grimes H, Given HF. An evaluation of preoperative CA 15-3 measurement in primary breast carcinoma. $\mathrm{Br} \mathrm{J}$ Cancer. 1995; 71:1288-1291.

7. Xie S, Ding X, Mo W, Chen J. Serum tissue polypeptidespecific antigen is an independent predictor in breast cancer. Acta Histochem. 2014; 116:372-376.

8. Zhang H, Li B, Zhao H, Chang J. The expression and clinical significance of serum miR-205 for breast cancer and its role in detection of human cancers. Int J Clin Exp Med. 2015; 8:3034-3043.

9. Misso G, Di Martino MT, De Rosa G, Farooqi AA, Lombardi A, Campani V, Zarone MR, Gulla A, Tagliaferri P, Tassone P, Caraglia M. Mir-34: a new weapon against cancer? Mol Ther Nucleic Acids. 2014; 3:194-205.

10. Pang RT, Leung CO, Ye TM, Liu W, Chiu PC, Lam KK, Lee KF, Yeung WS. MicroRNA-34a suppresses invasion through downregulation of Notch1 and Jagged 1 in cervical carcinoma and choriocarcinoma cells. Carcinogenesis. 2010; 31:1037-1044.
11. Shao C, Zhang J, Fu J, Ling F. The potential role of Brachyury in inducing epithelial-to-mesenchymal transition (EMT) and HIF-1alpha expression in breast cancer cells. Biochem Biophys Res Commun. 2015; 467:1083-1089.

12. Hermeking H. The miR-34 family in cancer and apoptosis. Cell Death Differ. 2010; 17:193-199.

13. Yang P, Li QJ, Feng Y, Zhang Y, Markowitz GJ, Ning S, Deng Y, Zhao J, Jiang S, Yuan Y, Wang HY, Cheng SQ, Xie D, et al. TGF-beta-miR-34a-CCL22 signaling-induced Treg cell recruitment promotes venous metastases of HBVpositive hepatocellular carcinoma. Cancer Cell. 2012; 22:291-303.

14. Imani S, Hosseinifard $\mathrm{H}$, Cheng J, Wei C, Fu J. Prognostic Value of EMT-inducing Transcription Factors (EMT-TFs) in Metastatic Breast Cancer: A Systematic Review and Metaanalysis. Sci Rep. 2016; 6:28587.

15. Imani S, Wei C, Cheng J, Khan MA, Fu S, Yang L, Tania M, Zhang X, Xiao X, Zhang X, Fu J. MicroRNA-34a targets epithelial to mesenchymal transition-inducing transcription factors (EMT-TFs) and inhibits breast cancer cell migration and invasion. Oncotarget. 2016 Feb 09. doi: 10.18632/ oncotarget.15214. [Epub ahead of print].

16. Erbes T, Hirschfeld M, Rücker G, Jaeger M, Boas J, Iborra S, Mayer S, Gitsch G, Stickeler E. Feasibility of urinary microRNA detection in breast cancer patients and its potential as an innovative non-invasive biomarker. BMC cancer. 2015; 15:193.

17. Agarwal S, Hanna J, Sherman M, Figueroa J, Rimm D. Quantitative assessment of miR34a as an independent prognostic marker in breast cancer. Br J Cancer. 2015; 112:61-68.

18. Mishra S, Srivastava AK, Suman S, Kumar V, Shukla Y. Circulating miRNAs revealed as surrogate molecular signatures for the early detection of breast cancer. Cancer Letts. 2015; 369:67-75.

19. John-Aryankalayil M, Palayoor ST, Makinde AY, Cerna D, Simone CB 2nd, Falduto MT, Magnuson SR, Coleman CN. Fractionated radiation alters oncomir and tumor suppressor miRNAs in human prostate cancer cells. Radiat Res. 2012; 178:105-117.

20. Eichelser C, Flesch-Janys D, Chang-Claude J, Pantel K, Schwarzenbach H. Deregulated serum concentrations of circulating cell-free microRNAs miR-17, miR-34a, miR155 , and miR-373 in human breast cancer development and progression. Clin Chem. 2013; 59:1489-1496.

21. Khan MA, Tania M, Wei C, Fu J. Relationship between transcription factor TWIST1 and microRNA34a in metastatic breast cancer cells. American Association for cancer Research. 2015.

22. Medimegh I, Omrane I, Privat M, Uhrhummer N, Ayari H, Belaiba F, Benayed F, Benromdhan K, Mader S, Bignon IJ, Elgaaied AB. MicroRNAs expression in triple negative vs non triple negative breast cancer in Tunisia: interaction with clinical outcome. PLoS One. 2014; 9:e111877. 
23. Wu MY, Fu J, Xiao X, Wu J, Wu RC. MiR-34a regulates therapy resistance by targeting HDAC1 and HDAC7 in breast cancer. Cancer Lett. 2014; 354:311-319.

24. Peurala H, Greco D, Heikkinen T, Kaur S, Bartkova J, Jamshidi M, Aittomaki K, Heikkila P, Bartek J, Blomqvist C, Butzow R, Nevanlinna H. MiR-34a expression has an effect for lower risk of metastasis and associates with expression patterns predicting clinical outcome in breast cancer. PLoS One. 2011; 6:e26122.

25. Roth C, Rack B, Müller V, Janni W, Pantel K, Schwarzenbach H. Circulating microRNAs as blood-based markers for patients with primary and metastatic breast cancer. Breast Cancer Res. 2010; 12:R90.

26. Zamora J, Abraira V, Muriel A, Khan K, Coomarasamy A. Meta-DiSc: a software for meta-analysis of test accuracy data. BMC Med Res Methodol. 2006; 6:31.

27. Tobias A. Assessing the influence of a single study in the meta-analysis estimate. Stata Techn Bull. 1999; 8:15-17.

28. Nugent M, Miller N, Kerin MJ. Circulating miR-34a levels are reduced in colorectal cancer. J Surg Oncol. 2012; 106:947-952.

29. Si H, Sun X, Chen Y, Cao Y, Chen S, Wang H, Hu C. Circulating microRNA-92a and microRNA-21 as novel minimally invasive biomarkers for primary breast cancer. J Cancer Res Clin Oncol. 2013; 139:223-229.

30. Wang F, Zheng Z, Guo J, Ding X. Correlation and quantitation of microRNA aberrant expression in tissues and sera from patients with breast tumor. Gynecol Oncol. 2010; 119:586-593.

31. Sapino A, Bussolati G. Is detection of endocrine cells in breast adenocarcinoma of diagnostic and clinical significance? Histopathology. 2002; 40:211-214.

32. Stieber P, Nagel D, Blankenburg I, Heinemann V, Untch M, Bauerfeind I, Di Gioia D. Diagnostic efficacy of CA 15-3 and CEA in the early detection of metastatic breast cancer-A retrospective analysis of kinetics on 743 breast cancer patients. Clin Chim Acta. 2015; 448:228-231.

33. Marrakchi R, Ouerhani S, Benammar S, Rouissi K, Bouhaha R, Bougatef K, Messai Y, Khadimallah I, Rahal K, Ben Ammar-Elgaaied A. Detection of cytokeratin 19 mRNA, CYFRA 21-1 (cytokeratin 19 fragments) in blood of Tunisian women with breast cancer. Int J Biol Markers. 2008; 23:238-243.

34. Duffy MJ, Walsh S, McDermott EW, Crown J. Biomarkers in Breast Cancer: Where Are We and Where Are We Going? Adv Clin Chem. 2015; 71:1-23.

35. Javeri A, Ghaffarpour $M$, Taha MF, Houshmand $M$. Downregulation of miR-34a in breast tumors is not associated with either p53 mutations or promoter hypermethylation while it correlates with metastasis. Med Oncol. 2013; 30:413.

36. Glas AS, Lijmer JG, Prins MH, Bonsel GJ, Bossuyt PM. The diagnostic odds ratio: a single indicator of test performance. J Clin Epidemiol. 2003; 56:1129-1135.
37. Dietze EC, Sistrunk C, Miranda-Carboni G, O'Regan R, Seewaldt VL. Triple-negative breast cancer in AfricanAmerican women: disparities versus biology. Nat Rev Cancer. 2015; 15:248-254.

38. Costantino NS, Freeman B, Shriver CD, Ellsworth RE. Outcome Disparities in African American Compared with European American Women with ER+HER2- Tumors Treated within an Equal-Access Health Care System. Ethn Dis. 2016; 26:407-416.

39. Walter SD. Properties of the summary receiver operating characteristic (SROC) curve for diagnostic test data. Stat Med. 2002; 21:1237-1256.

40. Moher D, Liberati A, Tetzlaff J, Altman DG, Group P. Preferred reporting items for systematic reviews and meta-analyses: the PRISMA statement. PLoS Med. 2009; 6:e1000097.

41. Gao Y, Cai Q, Huang Y, Li S, Yang H, Sun L, Chen K, Wang Y. MicroRNA-21 as a potential diagnostic biomarker for breast cancer patients: a pooled analysis of individual studies. Oncotarget. 2016; 7:34498-506. doi: 10.18632/ oncotarget.9142.

42. Lu Y, Yao J, Yu J, Wei Q, Cao X. The association between abnormal microRNA-10b expression and cancer risk: a meta-analysis. Sci Rep. 2014; 4:7498.

43. Tierney JF, Stewart LA, Ghersi D, Burdett S, Sydes MR. Practical methods for incorporating summary time-to-event data into meta-analysis. Trials. 2007; 8:16.

44. Williamson PR, Smith CT, Hutton JL, Marson AG. Aggregate data meta-analysis with time-to-event outcomes. Stat Med. 2002; 21:3337-3351.

45. Parmar MK, Torri V, Stewart L. Extracting summary statistics to perform meta-analyses of the published literature for survival endpoints. Stat Med. 1998; 17:2815-2834.

46. Moher D, Liberati A, Tetzlaff J, Altman DG. Preferred reporting items for systematic reviews and meta-analyses: the PRISMA statement. Ann Intern Med. 2009; 151:264-269.

47. Whiting PF, Rutjes AW, Westwood ME, Mallett S, Deeks JJ, Reitsma JB, Leeflang MM, Sterne JA, Bossuyt PM, QUADAS-2 Group-. QUADAS-2: a revised tool for the quality assessment of diagnostic accuracy studies. Ann Intern Med. 2011; 155:529-536.

48. Higgins JP, Thompson SG, Deeks JJ, Altman DG. Measuring inconsistency in meta-analyses. BMJ. 2003; 327:557-560.

49. Cornfield J. A method of estimating comparative rates from clinical data; applications to cancer of the lung, breast, and cervix. J Natl Cancer Inst. 1951; 11:1269-1275.

50. Egger M, Davey Smith G, Schneider M, Minder C. Bias in meta-analysis detected by a simple, graphical test. BMJ. 1997; 315:629-634. 